REVISTA DE DERECHO UNED, núm. 1, 2006

\title{
LA REVISIÓN DE LOS HECHOS PROBADOS EN EL RECURSO DE SUPLICACIÓN
}

\author{
MigueL ÁNgel Luelmo MiLlÁN
}

\begin{abstract}
Sumario: I. EL PROCESO EN LA INSTANCIA DESDE EL ACTO DE LA VISTA, LA SENTENCIA Y EL RECURSO DE SUPLICACIÓN CONTRA LA MISMA.-II. EL RECURSO DE SUPLICACIÓN Y LA REVISIÓN DE LOS HECHOS DECLARADOS PROBADOS EN LA SENTENCIA DE INSTANCIA.-A) Legitimación.-B) contenido de la propuesta de revisión: requisitos.-III. LAS PRUEBAS DOCUMENTAL Y PERICIAL COMO SOPORTE EXCLUSIVO DE LA REVISIÓN FÁCTICA DE LA SENTENCIA RECURRIDA.-A) La prueba documental y los medios mecánicos de reproducción de la palabra, imagen y sonido y otros instrumentos.-B) La prueba escrita y asimilada (dibujos, croquis, planos, mapas).-C) La prueba pericial.-IV. LA DOCUMENTAL APORTADA CON EL RECURSO DE SUPLICACIÓN.
\end{abstract}

\section{EL PROCESO EN LA INSTANCIA DESDE EL ACTO DE LA VISTA, LA SENTENCIA Y EL RECURSO DE SUPLICACIÓN CONTRA LA MISMA}

Como todos los recursos, el de suplicación del proceso laboral constituye un medio de impugnación de una resolución judicial de carácter principal. Con él se ataca el pronunciamiento de la sentencia recaída en la instancia, que una de las partes, o ambas, consideran no se ajusta a Derecho.

En una muy autorizada definición doctrinal, la sentencia es «un acto del órgano jurisdiccional en que éste emite su juicio sobre la conformidad o disconformidad de la pretensión de la parte con el de- 
recho objetivo y, en consecuencia, actúa o se niega a actuar dicha pretensión, satisfaciéndola en todo caso ${ }^{1}$, de manera que zanja la cuestión litigiosa y constituye, por ello, la resolución más importante en el proceso, que generalmente finaliza con ella.

Se trata de un silogismo jurídico donde de las premisas correspondientes que forman el relato fáctico y la fundamentación jurídica se obtiene la conclusión oportuna o fallo, y en cuanto éste da o niega, en todo o en parte, la razón a una de las partes litigantes, cualquiera de ellas que se considere injustificadamente perjudicada, puede, con base en el art 24 de la C.E. y en la normativa procesal que lo desarrolla, tratar de anularlo o revocarlo por medio del recurso pertinente, porque de ese precepto constitucional se deduce el derecho a acceder a la justicia ${ }^{2}$, que comprende, en principio, tanto el acceso a la instancia como a las vías de recurso en cuanto éstas suponen tramitaciones especiales a la crítica de los resultados procesales conseguidos en otra tramitación especial ${ }^{3}$.

El establecimiento del régimen de recursos es facultad del legislador, por lo que no hay a priori y en abstracto un derecho al recurso ${ }^{4}$, si bien puede considerarse como un principio general el de la recurribilidad de las resoluciones judiciales, en tanto en cuanto ello se considera como perfeccionamiento y cierre del sistema procesal. Y es en el proceso laboral donde el legislador ha establecido el recurso de suplicación, que no tiene parangón en el ámbito civil y que por su naturaleza y estructura está más próximo de la casación que de la apelación -de ahí la extendida denominación de «pequeña casación»- tal y como ha venido a reconocer el propio Tribunal Constitucional al declarar en varias ocasiones ${ }^{5}$ que en dicho recurso el órgano jurisdiccional que lo examina y resuelve debe limitarse a las concretas cuestiones planteadas por las partes, sin poder valorar de nuevo toda la prueba practicada ${ }^{6}$.

1 Guasp, J. «Derecho Procesal Civil», Edit. Instituto de Estudios Políticos, Madrid, 1961.

2 Rodríguez-Piñero y Bravo Ferrer, M. «Proceso de Trabajo y Justicia Constitucional», en «El Proceso Laboral. Estudios en homenaje al Profesor Luis- Enrique de la Villa Gil», VVAA, Edit. Lex Nova, 2001.

3 Guasp, J., obra citada.

${ }^{4} \mathrm{Al}$ respecto véase Folguera Crespo, J. «El derecho a los recursos legalmente establecidos. Recursos de suplicación y casación» en «El Proceso laboral en la jurisprudencia del Tribunal Constitucional», VV.AA. Cuadernos de Derecho Judicial. CGPJ, Madrid, 1996.

5 SS TC 18 y 294/1993, de 18 de enero y 18 de octubre, respectivamente, y 93/1997, de 8 de mayo.

6 V. Gil Suárez, L. «La nueva Ley de Enjuiciamiento Civil y el sistema de recursos de la Ley de Procedimiento Laboral», en "El Proceso Laboral. Estudios en homenaje al Profesor Luis Enrique de la Villa Gil», VV.AA., Edit. Lex Nova, 2001. 
Sobre la base de cuanto se acaba de decir y teniendo en cuenta que el art 97.2 de la LPL establece la obligatoriedad de que la sentencia de instancia declare expresamente los hechos que estime probados, se entiende y explica que posteriormente su art $191 \mathrm{~b}$ ) relacione como uno de los tres posibles objetos del recurso de suplicación - y el único que directamente interesa en este trabajoel de revisar los hechos probados, a la vista de las prueba documentales y periciales practicadas.

Esa pretendida revisión posee un carácter amplio, pues en ella se encuadran tanto la solicitud de supresión total o parcial de uno o varios de los ordinales del relato fáctico de la sentencia de instancia, como su modificación, o, en fin, la introducción de uno o más nuevos hechos con base en la prueba de las clases antedichas practicada en la instancia o en la documental que la parte recurrente consiga incorporar en vía de recurso con amparo en el contenido del art 231 de la LPL.

La prueba, pues, es, inicialmente, la practicada en juicio, que es el acto al que las partes han de acudir con todos los medios de que intenten valerse al efecto, según la advertencia que previamente se les hará en las correspondientes cédulas de citación, tal y como establece el art 82.2 de la LPL.

Y esa prueba se verá reflejada en el acta oportunamente levantada por el Secretario competente y suscrita, ante él y con él, por el Magistrado dirimente y las partes litigantes, de ahí que a ese documento haya de reconocérsele una subida importancia y conferírsele mucha mayor atención de la que se le suele prestar, no cabiendo olvidar al respecto que es en el acto de la vista donde tiene lugar la contestación a la demanda previamente ratificada o modificada por la parte actora, por lo que es entonces, y no antes, donde se expresan los argumentos de oposición a la misma, dependiendo de una correcta y completa transcripción que se recojan fiel y suficientemente las razones procesales y de fondo aducidas frente a dicha demanda, respecto de la cual, por el contrario, bastará, las más de las veces, con que se exprese que su autor se ratifica en ella, puesto que en el escrito que la contenga pueden $-\mathrm{y}$ deben - haberse expresado con la suficiente claridad y extensión los hechos y fundamentos de derecho sostenedores de la pretensión correspondiente.

La deficiente o ininteligible versión que el acta pueda recoger de cuanto ha acaecido en juicio pudiera y debiera motivar la correspondiente protesta e incluso la negativa a suscribirla por la indefensión que tales circunstancias sería susceptible de causar a alguna de 
las partes o a ambas, quienes de este modo prepararían el propio recurso de suplicación donde podría solicitarse, con tal motivo, la nulidad de actuaciones.

Ha de tenerse en cuenta, en fin, que el Juez de instancia puede denegar la práctica de alguna de las pruebas propuestas, lo que igualmente podría suponer, si fue con anterioridad al juicio, el recurso de reposición oportuno y si en él, la protesta correspondiente con el mismo teórico alcance anulatorio de las actuaciones en suplicación si, planteado de este modo, la Sala entendiese no justificada dicha decisión judicial, que debe fundarse debidamente, puesto que, en principio, el art 90.1 de la LPL permite "cuantos medios de prueba se encuentren regulados en la Ley, admitiéndose como tales los medios mecánicos de reproducción de la palabra, de la imagen y del sonido, salvo que se hubiesen obtenido, directa o indirectamente, mediante procedimientos que supongan violación de derechos fundamentales o libertades públicas».

No cabe duda de que, como se ha dicho ${ }^{7}$, el Juez ha de fallar en función de lo presenciado y oído durante la celebración del juicio, de lo que el acta es simple recordatorio, pero ello sólo es predicable de la instancia porque cuando del recurso se trata, la Sala, privada de la inmediación que caracteriza, entre otras notas, al proceso laboral en aquella fase, depende plenamente del acta para determinar tanto los términos en que finalmente quedó fijado el litigio, como la prueba que a lo largo del mismo se practicó y las conclusiones a que una y otra parte llegaron.

En concreto y por lo que hace a las pruebas admitidas y practicadas, el art 89.1.c) de la LPL exige que el acta efectúe un resumen suficiente de las de confesión -hoy, interrogatorio de las partes-y testifical, una relación circunstanciada de los documentos presentados o datos suficientes que permitan identificarlos en el caso de que su excesivo número haga desaconsejable dicha relación, debiéndose hacer constar igualmente las incidencias planteadas en el juicio respecto de tal prueba documental, esto es, al reconocimiento o no de la misma -en este último caso alegando su falsedad, o impugnándola, o, simplemente, desconociéndola oficialmente- todo lo cual exige dar traslado previo a cada parte de la documentación que aporte la contraria para su examen previo a la incorporación a los autos, tal y como establece el art 94.1 de la LPL, efectuando igualmente el acta

7 Valle Muñoz, F.A. «El acta de juicio en el proceso laboral», Actualidad Laboral n. ${ }^{\circ} 142005$. 
un resumen suficiente de los informes periciales, haciendo constar, en su caso, cuanto se haya resuelto en torno a las recusaciones de los peritos, y, en fin, un resumen de las declaraciones de los asesores en el caso de que su dictamen no haya sido elaborado por escrito e incorporado a los autos.

No cabe olvidar, en fin, lo que la LEC, de aplicación supletoria al proceso laboral conforme a la Disposición adicional primera, 1, de la LPL, establece al respecto en sus arts 146 y 147, conforme a los cuales, cuando la ley disponga que se levante acta, se recogerán en ella, con la necesaria extensión y detalle, todo lo actuado, si bien, con carácter general, las actuaciones orales en vistas y comparecencias se registrarán en soporte apto para la grabación y reproducción del sonido y de la imagen, en cuyo caso, el acta se limitará a consignar, junto con los datos relativos al tiempo y al lugar, las peticiones y propuestas de las partes y las resoluciones que adopte el tribunal, así como las circunstancias e incidencias que no pudiesen consignarse en aquel soporte, efectuándose la grabación bajo la fe del Secretario Judicial, a quien corresponderá la custodia de las cintas, discos o dispositivos en los que la grabación se hubiere efectuado, estableciendo la Disposición adicional tercera de la LEC un plazo de un año para que el Gobierno de la Nación y los Consejos de Gobierno de las CCAA que tengan transferidas las correspondientes competencias adoptarán las medidas necesarias para que los Juzgados y Tribunales dispongan de los medios materiales y de los recursos humanos precisos para la constancia de las actuaciones orales.

De todo ello se infiere que habrá de llevarse a cabo la reforma de la LPL para que, entre otras posibles modificaciones, se proceda a una nueva redacción de su precitado art 89 en términos coincidentes o semejantes a los de la Ley Procesal Civil, de tal manera que el contenido del acta escrita se vea aligerado, cuanto menos, de la necesidad de consignar de ese modo los resúmenes probatorios a los que actualmente alude en beneficio de una mayor y mejor constancia de todos y cada uno de los extremos que conforman su natural contenido y en evitación de los inconvenientes del actual sistema y de los riesgos de anulación de actuaciones a que se ha hecho referencia precedentemente.

No obstante, y hasta tanto tal reforma se produce, puede entenderse, en función de ese carácter subsidiario de la LEC, que ya es posible aplicar el procedimiento que la misma consigna en el ámbito procesal laboral si el órgano jurisdiccional correspondiente tuviese a su disposición los medios necesarios para ello. 
Por otra parte, es también posible que por la vía de las diligencias para mejor proveer ${ }^{8}$, sea el propio Juez de instancia el que acuerde de oficio la práctica de pruebas, aunque con intervención de las partes ${ }^{9}$ y ello terminado el juicio y dentro del plazo para dictar sentencia, según refiere el art 88.1 de la LPL, que confiere a aquél una gran libertad en este punto, al determinar que podrá ordenar «cuantas pruebas estime necesarias», lo cual constituye una de las diferencias existentes con las diligencias finales (en principio, a instancia de parte, aunque excepcionalmente también de oficio) del proceso civil, cuya norma reguladora establece en su art 435.1 una limitación de los motivos al respecto ${ }^{10}$.

Estas pruebas judiciales también pueden, en principio y si de la documental o pericial se trata, servir de base a la revisión fáctica propuesta en el recurso de suplicación, siempre y cuando la parte recurrente haya tenido oportunidad de efectuar en la instancia - y lo haya hecho- las alegaciones que estimase procedentes y que éstas no hubiesen sido acogidas, en todo o en parte, por el Juzgador, de modo que el motivo suplicacional constituiría - en gran manera al menos - una reiteración, incluso perfeccionada - y hasta argumentando «a contrario sensu» y con base en la propia prueba de como lo hubiese hecho el Juzgador de instancia al ponderarla, lo cual, no obstante, posiblemente tendría mejor ubicación en un motivo amparado en el apartado c) del art 191 de la LPL_ de lo ya expuesto a aquél con ocasión del traslado que hubiese dado a dicha parte de la práctica de esa/s prueba/s.

La valoración del material probatorio, en fin, incumbe, en exclusiva, al Juez ante el cual se practicó o aportó al procedimiento, sin que se halle vinculado en este punto y extremo por el resumen que el acta recoge, pues, como asimismo ha advertido la doctrina, "matices importantísimos de la oralidad son intranscribibles en esos resúmenes»" ${ }^{11}$, de ahí que sea, cuanto menos conveniente, que

${ }^{8}$ A ellas se refiere la S.TS, Sala 4. ${ }^{a}$, de 10 de marzo de 1986, señalando que si bien es cierto que el Juez no puede utilizarlas para aportar nuevos hechos al proceso ni para suplir la inactividad y falta de diligencia de las partes, debe, no obstante, evitar que por falta de pruebas no prevalezca la justicia.

${ }_{9}$ De no darse audiencia a las mismas cabría que la perjudicada solicitase, con éxito, la nulidad de la sentencia, tal y como se refleja en la S.TS, Sala 4 . $^{\mathrm{a}}$, de 15 de abril de 2003.

${ }^{10}$ Sobre esta cuestión, Alonso García, R.M. ${ }^{a}$, «El proceso de trabajo y la nueva Ley de Enjuiciamiento Civil», Edit. Civitas, $1 .^{2}$ edic. 2001, págs 86-88.

11 Valle Muñoz, F.A., trabajo mencionado, con cita de Rodríguez Santos, B. y Cebrián Badía, F.J. «Comentarios a la Ley de Procedimiento Laboral», Tomo II, edit. Lex Nova, Valladolid, 1991. 
en la fundamentación jurídica de su sentencia se extienda en las consideraciones que entienda oportunas para aclarar las posibles deficiencias del acta al respecto, e integrar del modo más completo posible su contenido, haciendo así más comprensible también el trayecto o recorrido dialéctico de la resolución judicial del litigio.

\section{EL RECURSO DE SUPLICACIÓN Y LA REVISIÓN DE LOS HECHOS DECLARADOS PROBADOS EN LA SENTENCIA DE INSTANCIA}

\section{A) LEGITIMACIÓN}

Dictada sentencia en la instancia e impugnada en tiempo y forma cuando sea susceptible de ello conforme al art 189 de la LPL, ha de partirse del contenido del propio recurso para determinar previamente si en él se propone, o no, alguna revisión fáctica, lo cual nos lleva de antemano a plantear y resolver la cuestión de la legitimación para recurrir.

$\mathrm{Al}$ respecto, la jurisprudencia más reciente la ha reconocido a cualquiera de las partes cuando intenta variar de algún modo el contenido de la sentencia que impugna, suavizando así el rigor de su tesis anterior ${ }^{12}$, porque, según sostiene, la verdadera causa del recurso es el interés del recurrente, siempre que sea personal, objetivo y directo, existiendo el gravamen "respecto de cualquier diferencia perjudicial entre lo pedido por la parte y lo concedido en la resolución judicial, pudiendo ser muy variado y afectar a aspectos accesorios a la pretensión principal», línea permisiva que considera plasmada en el art 448 de la LEC.

En consecuencia, también quien haya sido absuelto en la sentencia de instancia pero entienda que la resultancia fáctica de la misma puede perjudicarle directa o indirectamente, podrá formular su recurso instando la revisión de los hechos declarados probados en aquélla. De no hacerlo así, lo que no parece factible es que pueda proponer esa misma revisión en el escrito de impugnación del recurso que haya formulado la parte contraria y donde únicamente cabría que combatiese (o admitiese) la propuesta revisora de la misma.

12 S.TS, Sala 4. ${ }^{\text {a }}$, de 10 de noviembre de 2004, que matiza y limita el alcance de la dictada en Sala General de 21 de febrero de 2000. 


\section{B) CONTENIDO DE LA PROPUESTA DE REVISIÓN: REQUISITOS.}

En cuanto a la siguiente cuestión, relativa al propio contenido de la proposición revisora, es también la jurisprudencia ${ }^{13}$ la que señala que la declaración de hechos probados debe ser concreta y detallada en el grado mínimo requerido para que los litigantes puedan proceder a su impugnación en todos los aspectos relevantes del proceso y para que los órganos jurisdiccionales de suplicación o de casación puedan comprender cabalmente el debate procesal y resolver sobre el mismo en los términos previstos en la ley, de modo que dicha declaración constituye la base indispensable para el examen del derecho aplicable.

Por su parte, la revisión que pretenda el recurrente con base en la documental o pericial practicada, está obligada ${ }^{14}: 1^{\circ}$ ) a fijar qué hecho o hechos han de adicionarse, rectificarse o suprimirse, $2 .^{\circ}$ ) a precisar los términos en que deben quedar redactados los hechos probados y su influencia en la variación del signo del pronunciamiento, y, 3. ${ }^{\circ}$ ), a citar concretamente la prueba de esa clase que, por sí sola, demuestre la equivocación del juzgador de una manera manifiesta, evidente y clara.

Antes de entrar en su examen, es oportuno reseñar, en primer lugar, que dicha revisión es fundamentalmente propia del recurso de suplicación y no cabe en el de casación más que por la estrecha vía del art 205.d) de la LPL ${ }^{15}$, sin que, por otra parte, y como regla general, quepa en aquél la anulación de la sentencia de instancia por insuficiencia de hechos probados, que sólo es posible como «ultima ratio" para el caso de que las omisiones en que haya incurrido la decisión judicial no puedan subsanarse por una u otra vía, según tiene declarado la jurisprudencia ${ }^{16}$.

Sobre esta base, la propuesta de revisión exige, evidentemente, que la sentencia recurrida tenga un apartado dedicado a enumerar los hechos que sirven de fundamento fáctico a su resolución, porque

13 SS TS, Sala $4 .^{\text {a }}$, de 18 de enero y 31 de octubre de 1988 y 22 de enero de 1998 , entre otras.

${ }^{14}$ V., p.e., SS. TS, Sala $4 .^{\mathrm{a}}$, de 3 de marzo de 1998 y 11 de diciembre de 2003.

15 Al que cabe poner en relación con el 231 de la misma norma relativo a la excepcional admisión de documentos en trámite de recurso, al hallarse comprendido dicho precepto en el Capítulo V del Libo III de la LPL referente a las disposiciones comunes a los recursos de suplicación y casación.

16 SS TS Sala 4. ${ }^{a}$, de 17 de octubre de 1989 y 22 de octubre de 1991. 
así se infiere expresamente del precitado art 97.2 de la $L^{2} L^{17}$, de manera que si no fuese de este modo, se impondría necesariamente la nulidad de la resolución misma por tratarse de una cuestión de orden público procesal, aun cuando actualmente existe el problema de que si la nulidad no se ha solicitado por alguna de las partes, no es posible acordarla de oficio en vía de recurso por tenerlo establecido así el art 240.2, párrafo segundo, de la LOPJ en la redacción dada al precepto por el apartado cincuenta y siete del art. único de la LO 19/2003, de 23 de diciembre, que reduce dicha posibilidad a la petición de alguno de los litigantes, armonizándolo con lo establecido en el art 227.2, segundo párrafo, de la LEC.

$Y$ aunque resulta impensable que en un caso tan procesalmente extremo como el de una sentencia de instancia de la Jurisdicción Social que carezca de ese fundamental contenido ninguno de los contendientes (especialmente la parte recurrente, que es a quien, en principio, única o muy fundamentalmente perjudicaría) mencione tal ausencia con ocasión de la impugnación de dicha resolución, lo cierto es que, ante tal hipotética eventualidad, del mismo modo que ante la mucho más factible de que la Sala considere que no existen datos suficientes en dicho relato para resolver y no se hayan propuesto con el recurso, o incluso cuando entienda que no se ha integrado debidamente el litiscosorcio correspondiente, no hay una solución normativamente prevista, pues precisamente lo que la ley hace es proscribir la declaración de oficio de la nulidad de actuaciones que no haya sido solicitada en el recurso.

Ello se trata de solventar en la práctica acudiendo al expediente de habilitar la fórmula contenida en el primer párrafo de ese mismo apartado 2 de los preceptos en cuestión (240 LOPJ y 227 de la LEC) instando la Sala de las partes y del Ministerio Fiscal - este último, aunque no haya sido parte en el proceso y como salvaguarda de la legalidad - mediante resolución motivada donde se expongan, sin prejuzgar, las deficiencias que entienda existentes y su alcance, el parecer de aquéllos acerca de la posibilidad de acordar dicha nulidad y si a la vista de tal exposición, alguno de los consultados así lo admitiese, se entenderá solicitada expresamente tal medida, que podría ser acordada acto seguido en la sentencia que recaiga para decidir el recurso en cuestión, lo que comportaría la devolución de las actuaciones a la instancia para la subsanación pertinente.

17 Precepto que resulta oportuno poner en relación con el afro 248.3 de la LOPJ y con el 209.2. de la LEC. 
Conviene asimismo dejar constancia de que la revisión que se inste puede dirigirse no sólo a la declaración de hechos probados propiamente dicha sino también a la fundamentación jurídica de la sentencia de instancia, cuando ésta contenga, indebida, pero eficazmente, algún elemento fáctico de trascendencia, porque se ha reiterado jurisprudencialmente que tal irregularidad no tiene la importancia necesaria para ocasionar alguna consecuencia procesal ${ }^{18}$.

Y retomando la cuestión, el primero de tales requisitos supone tres posibilidades: mantener íntegra la declaración fáctica de la resolución recurrida pero añadiéndole nuevos hechos que la completen y en los que, evidentemente, la parte recurrente basará su inmediata motivación jurídica, o bien eliminar y sustituir, en todo o en parte, por una nueva redacción el hecho o hechos de la sentencia atacados con el recurso, de manera que ello arroje un resultado cuya valoración posterior haya de ser sustancialmente distinta de la efectuada en la instancia, o, en fin, suprimir, sin más, uno o varios hechos, con lo que igualmente el panorama histórico cambie de manera decisiva.

Aparentemente, no hay un límite al alcance de la reforma propuesta pero difícilmente podrá admitirse la sustitución de todo el relato por uno íntegramente nuevo, porque ello parece más propio de la nulidad de la sentencia de instancia y su plena reconstrucción en suplicación, o lo que es igual, su inexistencia, puesto que desaparecería toda traza de la misma, lo que ni siquiera su propia revocación le niega en términos absolutos, aunque suponga la cesación de sus efectos.

Por lo que hace a los términos de la redacción fáctica solicitada y la explicación de su influencia en la decisión de la controversia, ha de quedar excluído:

a) Todo aquello que no sea un dato en sí, como los preceptos de normas reglamentarias de carácter interno o del convenio colectivo aplicable ${ }^{19}$, y, en definitiva, cualquier concepto jurídico ${ }^{20}$.

18 Por todas, vid. STS, Sala $4 .^{\text {a }}$, de 14 de diciembre de 1998, que señala que «las omisiones del relato de hechos probados.........pueden quedar suplidas por afirmaciones de naturaleza histórica que se hagan en los fundamentos jurídicos».

19 V. S.TS, Sala $4 .^{\text {a }}$, de 27 de octubre de 2004.

20 En tal sentido cabe significar que es muy común la confusión que en los litigios sobre prestaciones de Seguridad Social existe entre bases de cotización (un hecho, pues se trata de lo cotizado mensualmente a la entidad competente) y base reguladora (concepto jurídico) haciéndose figurar las más de las veces esta última en la declaración de hechos probados cuando es el resultado o consecuencia del cómputo de las primeras durante el período exigido en cada caso por la normativa de aplicación, por lo que, en puridad, sólo las bases de cotización podrían aparecer en la declaración fáctica y no la base reguladora. 
b) Los juicios de valor, que predeterminan el fallo, cuya ubicación corresponde en la motivación jurídica del recurso, la cual es de todo punto ineludible, sin que quepa un recurso que sólo contenga o se reduzca a una o varias propuestas revisoras, pues de esta manera quedaría incompleto el esquema dialéctico de la impugnación resolutoria.

c) Aquellos hechos que sean notorios y generalmente conocidos o aquellos otros en los que se manifiesten plenamente de acuerdo las partes, por lo que aunque no consten en la sentencia de instancia no será necesario - ni siquiera oportuno- solicitar que figuren en ella.

d) Hipótesis, conjeturas o elucubraciones ${ }^{21}$, de tal modo que lo no acontecido, por posible, probable o incluso seguro que pudiera resultar de darse las condiciones correspondientes (no concurrentes en el caso), no ha llegado a ser, y, por tanto, está fuera de esa relación ${ }^{22}$.

e) Los hechos negativos ${ }^{23}$ cuando equivalen a no acaecidos, porque el "no hecho» es, por su propia definición, algo inexistente, y, como tal, por tanto, carente de virtualidad y si no se exige su demostración, por constituir una "probatio diabolica», parece lógico que tampoco pueda pretender imponerla quien no estaría obligado a ella, máxime cuando la cuestión, en la mayor parte de las ocasiones, se reduce a un problema de redacción que se puede subsanar con una afirmación de lo contrario. Por el contrario, cabe proponer un hecho negativo cuando manifiesta una carencia o una conducta contraria a la legalmente exigida.

f) En definitiva, todo aquello que no tenga la consideración de hecho en la acepción de esta última palabra como "cosa que sucede ${ }^{24}$, sirviendo, por el contrario, su inclusión inicial para solicitar la supresión de lo indebidamente inserto en tal lugar.

${ }^{21}$ V. ss. Sala de lo Social del TSJ de Castilla-León (Valladolid), de 16-3-04 y del de Madrid (Sección 2. ${ }^{a}$ ), de 28-12-04.

${ }^{22}$ V.,p.e., s. Sala de lo Social del TSJM, Sección 4. ${ }^{\text {a }}$, de 2-11-04, que así lo refiere en su segundo fundamento de derecho.

${ }_{23}$ Acerca de la clasificación de los hechos en positivos y negativos y en general en relación con todo el tema, puede verse Molins García Atance, J., «El Recurso de Suplicación. La Revisión de los Hechos Probados», Edit. Thomson-Aranzadi, 2005 págs 140-144. Esta reciente obra, que está basada en la memoria de una tesis doctoral, constituye, evidentemente, por su extensión, densidad, pormenorización y exhaustividad, la más importante aportación doctrinal a la materia de su título hasta el presente.

${ }^{24}$ Diccionario de la Lengua Española, de la Real Academia de la Lengua, vigésimo primera edición, acepción 10. 
De otro lado, la redacción referida ha de ser inteligible y relacionada con el resto del relato para hacer de él un todo unitario directamente integrado en el contexto dialéctico de la sentencia y ha de suponer, según la jurisprudencia, una alternativa al hecho que conste en el relato de la sentencia o un propuesta de supresión total o parcial del mismo ${ }^{25}$.

Sentado cuanto antecede, la explicación de la trascendencia de la propuesta supone aportar un mínimo argumental dirigido a la convicción judicial de que el/los hecho/s en cuestión constituye/n un eslabón en la cadena de acontecimientos con alguna repercusión en la tesis que se sostiene con el recurso, siendo lo más conveniente que la Sala efectúe una interpretación amplia de ese valor desde el momento en que cabiendo teóricamente recurso contra la sentencia de suplicación, lo que en ésta se estimase irrelevante podría, sin embargo, ser considerado de importancia, mayor o menor, en casación, de manera que bastaría con que teórica o hipotéticamente pueda tener trascendencia, aunque la Sala no la aprecie en el enjuiciamiento de los términos concretos del recurso, para que, no obstante, admitiera como probado/s el/los hechos pretendido/s con sólo resultar acreditado/s con la prueba que se aduzca en su apoyo.

Finalmente, por lo que respecta a la concreta cita de la prueba documental o pericial que demuestre la equivocación del Juzgador, habrá de partirse, evidentemente, de la constancia de la prueba en autos, no pudiendo admitirse que no obre en ellos sino en un procedimiento diferente al que el propio Juzgador de instancia se haya remitido sin acordar su unión al que se está resolviendo, lo que podría ser motivo de nulidad de actuaciones si no pudiese subsanar de algún modo tal defecto la propia Sala ${ }^{26}$, debiendo hacerse una designación específica de lo correspondiente, señalando, por lo que hace a la primera de dichas pruebas, su ubicación concreta, esto es, cuáles sean esos documentos y el lugar que ocupan en los autos mediante la referencia exacta de los folios, no bastando, por tanto, con una remisión en bloque o con manifestar que obran en el procedimiento ${ }^{27}$, siendo oportuno incluso subrayar el apartado o lugar determinado donde se contenga lo que se pretende incluir, y lo mismo en cuanto a

${ }^{25}$ V. SS TS Sala 4. ${ }^{2}$, de 31 de marzo de 1993, 4 de noviembre de 1997 y 20 de enero de 2004 , entre otras.

${ }^{26}$ s. Sala de lo Social del TSJ de Castilla-León (Valladolid, Sección 1. ${ }^{a}$ ), de 16-3-04

27 V., p.e., ss. Sala de lo Social del TSJ de Andalucía (Granada), de 10-2-04; de Aragón de 1-4-04 (con cita de las del mismo Tribunal de 2-11-01 y 30-9-02), de Galicia, de 9-7-04 (con cita de la de 25-10-01 y las que en ella, a su vez, se mencionan) o del País Vasco, de 16-11-04. 
la pericial, que deberá previamente haber sido adverada en juicio por su autor, quien, muy probablemente, habrá tenido, además, que responder a las preguntas que se le hayan formulado de contrario o por el propio Juzgador en aquel instante, todo lo cual, en su caso, habrá de constar en el acta levantada al efecto y deberá asimismo de señalarse al proponer la revisión fáctica.

\section{LAS PRUEBAS DOCUMENTAL Y PERICIAL COMO SOPORTE EXCLUSIVO DE LA REVISIÓN FÁCTICA DE LA SENTENCIA RECURRIDA}

\section{A) LA PRUEBA DOCUMENTAL Y LOS MEDIOS MECÁNICOS DE REPRODUCCIÓN DE LA PALABRA, IMAGEN Y SONIDO Y OTROS INSTRUMENTOS}

Como ya se ha dicho, las pruebas de declaración o interrogatorio de parte/s y la testifical, no son revisables en suplicación, ni tampoco lo son el posible reconocimiento judicial o las presunciones ${ }^{28}$, al no mencionarlas la norma (precitado art 191 b) de la LPL) a tal fin, que sólo cita «las pruebas periciales y documentales practicadas" ${ }^{29}$.

De ello se infiere la gran importancia que éstas tienen en el ámbito procesal social, exigiendo, por su parte, el art 194.3 de la LPL que en el escrito de interposición de recurso se señalen «de manera suficiente para que sean identificados los documentos o pericias en que se base el motivo de revisión de los hechos probados que se aduzca", lo que, por vía indirecta, viene a ratificar y reforzar la exclusión, a ese fin, de las restantes pruebas practicadas. Se discute si

${ }^{28}$ A estas últimas, en realidad y de modo más acorde con su intrínseca naturaleza de proceso mental deductivo, no se les da ya oficialmente el carácter de prueba que los arts 1.249 a 1253 del C.C. (derogados por la Disposición Derogatoria Única de la vigente LEC) les reconocían al estar encuadrados en el Capítulo V (De la prueba de las obligaciones) del Título I de su Libro IV, condición que doctrinalmente se venía negando hacía mucho tiempo -o cuanto menos, cuestionando o matizando declarándolas "pruebas indirectas", aunque también autores muy caracterizados, como Guasp, obra citada, sostenían su verdadero carácter de medio probatorio-y así, la propia LEC vigente se refiere a ellas separadamente de las pruebas propiamente dichas, al titular el Capítulo VI del Título I de su Libro II «De los medios de prueba y las presunciones».

29 Aunque la doctrina admite excepcionalmente la posibilidad de denunciar el error en la apreciación de los medios de prueba distintos de la documental y pericial al amparo del art 191c) de la LPL alegando la vulneración de las normas jurídicas que regulan la apreciación de estos medios probatorios. Véase al respecto Molins GarcíaAtance J., obra citada, pág.76. 
los medios mecánicos de reproducción de la palabra, de la imagen y del sonido y los instrumentos de archivo, conocimiento o reproducción de datos relevantes para el proceso, valorados conforme a las reglas de la sana crítica (arts 382.3 y 384.3 de la LEC) pueden o no considerarse como una manifestación o especie de la prueba documental a estos efectos revisorios, no siendo la cuestión doctrinalmente pacífica pues hay autores que así lo entienden ${ }^{30}$, mientras que otros lo consideran «dudoso» ${ }^{31}$, señalando que la respuesta dependerá del concepto extensivo o estricto que se tenga del documento y precisando en cuanto a los soportes informáticos, que el problema radica no tanto en la representación gráfica cuanto en la naturaleza del propio soporte, diferente del papel o materia similar, y el temor de que pudiera ser objeto de manipulaciones que lo invalidasen como medio de prueba con garantías de autenticidad y exactitud, por todo lo cual se opta por considerar todos esos mecanismos como medios de prueba autónomos y diferentes de la prueba documental con apoyo en los arts 229 y 333 de la LEC, concluyendo que por ello, los tan reiterados instrumentos mecánicos o informáticos de reproducción y/o acumulación de datos no tienen cabida en la actual redacción de los arts 191.b) y 194.3 de la LPL, y que, hasta que no se proceda a su reforma, no podrán sustentar la revisión fáctica a que tales preceptos aluden.

Tampoco existe una jurisprudencia decidida en la materia, siendo de destacar, no obstante, alguna sentencia, anterior a la vigente LEC $^{32}$, que refiriéndose a las cintas magnetofónicas, videos y cualesquiera otros medios de reproducción hablada o representación visual del pensamiento humano los cataloga, con base en el C.C. (derogado art 1.215) y anterior Ley Rituaria (art 578) como prueba documental asimilable a los documentos privados.

De cualquier modo, si de la admisibilidad de tales medios como prueba en la instancia no existe duda alguna, siendo ya abundantes las sentencias de suplicación que hacen referencia a los mismos sin plantearse, por no exigirlo el contenido del recurso correspondiente,

${ }^{30}$ V. p.e., Alonso García, R.M. ${ }^{\text {a }}$, obra mencionada, pág. 111, con cita del punto XI de la propia Exposición de Motivos de la LEC (nota 128) y de Ormazábal Sánchez, G. "La prueba documental y los medios e instrumentos idóneos para reproducir imágenes o sonidos o archivar y conocer datos», Edi. Rev. La Ley 2000. (nota 129).

31 Cavas Martínez, F. «El recurso laboral de suplicación y la nueva Ley de Enjuiciamiento Civil", en "Incidencia de la Ley de Enjuiciamiento Civil en el Procedimiento Laboral», VVAA Rúios Salmerón ,B. y Sempere Navarro, A.V., coordinadores), Edit. Aranzadi 2001.

32 S. TS, Sala 4. ${ }^{\text {a }}$, de 12 de junio de 1999. 
la cuestión relativa a la naturaleza de la prueba sino tan solo la referente al modo de su obtención ${ }^{33}$, conforme o contrario a los derechos fundamentales a la dignidad y a la intimidad - como las que se han pronunciado sobre el control videográfico del lugar de trabajo ${ }^{34}$ en sentido positivo o negativo ${ }^{35}$, o las relativas a la intervención empresarial del software del trabajador para determinar el uso dado al mismo durante la jornada laboral ${ }^{36}$, entre otras- parece más lógico entender, en beneficio de una más completa concepción de lo que el recurso en sí mismo considerado supone, que no se dé una interpretación restringida - aunque haya una base hermenéutica de la legalidad vigente más o menos razonable para sostenerla- sino amplia al término y concepto "documento», tal y como mayoritariamente viene entendiendo esa misma jurisprudencia menor ${ }^{37}$, hasta que se produzca la reforma de la LPL que, es más que probable, consagrará definitivamente esta segunda tesis, porque, como expresamente refiere el ya citado apartado XI de la Exposición de Motivos de la LEC, «no habrá de forzarse la noción de prueba documental para incluir en ella lo que se aporte al proceso con fines de fijación de la certeza de los hechos que no sea subsumible en los restantes medios de prueba...........y no es de excluir sino que la ley lo prevé, la utilización de nuevos instrumentos probatorios como soportes, hoy no convencionales, de datos, cifras y cuentas, a los que, en definitiva,

${ }^{33} \mathrm{Al}$ respecto, vid. Baylos Grau, A. «Medios de Prueba y Derechos Fundamentales. Especial referencia a la tutela de esos derechos ", en "la Prueba en el proceso laboral», VVAA, Cuadernos de Derecho Judicial n. ${ }^{\circ} 23,1997$, CGPJ., que sostiene que la inadmisibilidad de la prueba que vulnere tales derechos se acordará por el Juez de oficio o a instancia de parte........Sucede sin embargo que en muchas ocasiones no siempre es posible conocer anticipadamente la existencia de una prueba obtenida ilícitamente, por lo que ha de ser en el momento de formación del razonamiento judicial y de la valoración conjuntas de la prueba aquel en el que ésta, de estimarse ilícita, debe descartarse. En todo caso, es la vúía del recurso "la garantía final de la cerencia de efecto de la prueba en cuestión". La dicción legal veda también cualquier intento de subsanación de la prueba conseguida ilícitamente con vulneración de derechos fundamentales a través de la utilización de ulteriores medios de prueba lícitos sobre la base de las informaciones recogidas de aquella inaceptable manera. La expresión legal (se refiere al art 90.1 de la LPL) que incluye expresamente la posibilidad de obtener «indirectamente» pruebas mediante procedimientos lesiovos de derechos fundamentales, así lo permite afirmar».

${ }^{34} \mathrm{~s}$. Sala de lo Social del TSJ de Madrid (Sección 2.a) de 6-7-04 y Sala de lo Social del TSJ de Navarra de 27-11-04.

${ }^{35}$ ss. Sala de lo Social del TSJ del País Vasco, 21-12-04 y Sala de lo Social del TSJ de Cataluña, 11-3-04.

${ }^{36}$ s. Sala de lo Social del TSJ de Castilla y León (Valladolid), 8-11-04.

${ }^{37}$ Vid,.p.e., ss. Sala de lo Social del TSJ de Andalucía (Málaga) y País Vasco de 28 1 y 14-3-00, respectivamente, Sala de lo Social del TSJ de Galicia, de 3-5-02 y Sala de lo Social del TSJ de Madrid (Sección 2. a) de 6-7-04, entre otras. 
haya de otorgárseles una consideración análoga a la de las pruebas documentales». Y es ese término ("instrumento») utilizado varias veces en dicha Exposición, el que puede dar la pauta definitiva para solventar la cuestión, en tanto en cuanto sería susceptible de identificarlo con el medio o la materia del que se sirve o está hecho el documento propiamente dicho, porque éste, como se ha manifestado con autoridad difícilmente discutible ${ }^{38}$, puede hallarse constituído de cualquier materia, siempre que su índole no le imponga imposibilidad de desplazamiento hasta el órgano jurisdiccional.

Así parece deducirse, por otra parte, de la parigualación que efectúa el art 270 de la LEC entre documentos y «medios e instrumentos» en orden a la presentación, en ese proceso, de los relativos al fondo del asunto en un momento posterior al inicial, con lo que de relación tiene ello con el proceso laboral y, en concreto, con el art 231 de la Ley que lo rige, de lo que se sigue que si cabe, por esta vía, considerarlos incluídos en tal precepto, se les está confiriendo capacidad revisora, no cabiendo olvidar, por otra parte, como se ha señalado con tino por la doctrina judicial ${ }^{39}$, que si se aportan al acto de la vista reproducciones o copias en soporte papel obtenidas de fuentes informáticas, resultaría paradójico negar la eficacia revisora del original y admitir la de su copia o materialización.

El hecho de que el art 90.1 de la LPL distinga entre los medios de prueba "que se encuentren regulados en la ley» y los meritados «medios mecánicos de reproducción", no obedece, probablemente, más que a que está añadiendo estos últimos a los ya mencionados en la LEC de 1881 y en los arts del C.C. relativos a la prueba de las obligaciones (art 1.214 y ss, los dos primeros derogados también, entre otros, por la nueva LEC) textos que no podían tener en cuenta, por desconocidos, tales instrumentos, de manera que es ahora la LPL la que se queda rezagada en este punto respecto de la nueva Ley Procesal general, pero ello no tiene por qué significar que la diferenciación de tales pruebas constituya una evidencia o siquiera un indicio de que poseen, al cabo, una naturaleza igualmente diferente de la prueba documental sino tan solo que no son prueba escrita «stricto sensu».

No cabe olvidar, por otro lado, que la LEC, en su condición subsidiaria, es también de aplicación al proceso laboral en cuanto al valor probatorio de los instrumentos de filmación, grabación y seme-

${ }^{38}$ Guasp, J. obra citada, pág. 467.

39 Precitada s. del TSJ de Galicia, Sala de lo Social, de 3-5-02. 
jantes (art 382.3) y de los instrumentos que permitan archivar, conocer o reproducir datos relevantes para el proceso (art 384.3) de los que dice que se enjuiciarán conforme a las reglas de la sana crítica, lo que si los acerca en este aspecto valorativo a la prueba pericial, no impide, en cualquier caso, su acceso a la suplicación.

La indeterminación, en fin, que supone calificar los referidos medios e instrumentos como un "medio autónomo de prueba» ${ }^{40}$-expresión que constituye un auténtico cajón de sastre donde cabe todo lo que no sea una de las pruebas clásicas en sentido estricto- y la inseguridad que siempre comportará esa falta de auténtica definición, es un argumento más en pro de la naturaleza documental de los mismos, al menos mientras no haya un pronunciamiento normativo expreso acerca de su eficacia revisora.

\section{B) LA PRUEBA ESCRITA Y ASIMILADA (DIBUJOS, CROQUIS, PLANOS, MAPAS)}

La LPL, al referirse a la prueba documental, únicamente dice (art 94) que de la que se presente se dará traslado a las partes en el acto del juicio, para su examen y que los documentos pertenecientes a las mismas deberán aportarse al proceso, si hubieran sido propuestos como medio de prueba por la contraria y haya sido admitido por el Juez o Tribunal, de tal manera que si no se presentaren sin causa justificada, podrán estimarse probadas las alegaciones hechas por la parte solicitante en relación con la prueba acordada, es decir que tras una referencia tácita a la prueba de esta clase que pueda presentar cada litigante en defensa de su respectiva tesis y pretensión, alude a la que cualquiera de las partes exija a la otra por tenerla ésta en su poder y que si no la trajese al procedimiento por una causa razonable, podrá hacerse bueno el alegato que sobre la misma hubiese efectuado quien la pedía.

Es, por tanto, la LEC la norma que desde el punto de vista del Derecho positivo procesal lleva a cabo la regulación general de dicha prueba, refiriéndose a la misma en las Secciones $2^{\mathrm{a}}$ a $4^{\mathrm{a}}$ del Capítulo VI del Título I de su Libro II (arts 317 a 334) estableciendo inicialmente ya la distinción entre documentos públicos y privados, cada una de cuyas clases es regulada en las dos primeras secciones referidas para dedicar la última a las disposiciones comunes a una y otra.

${ }^{40}$ Así los considera una parte de la doctrina y también algunas sentencias del TS, como la de 15 de febrero de 1984. 
Partiendo de la perniciosa e impropia bicefalia normativa en la materia, que la vigente $\mathrm{LEC}$ no ha querido ${ }^{41}$ o podido suprimir del todo manteniendo vigentes todavía una serie de preceptos al respecto del Código Civil al no haber sido incluídos en su Disposición Derogatoria Única, cabe señalar que al igual que en la LEC de 1881, no se da en la actual una definición de documento a efectos probatorios, si bien ello se palía parcialmente con la que proporciona respecto de los documentos públicos el art 1.216 del C.C., que dice que ostentan dicho carácter «los autorizados por un Notario o empleado público competente con las solemnidades requeridas por la ley». La LEC complementa tal definición relacionándolos — como también ya hiciera la anterior Ley Procesal en su art 596- a lo largo de los seis números que contiene el primero de sus preceptos (art 317).

Se consideran privados, por exclusión, los que no se hallen catalogados como públicos (art 324), limitándose el art 1.225 del C.C. a señalar respecto de ellos que «el documento privado, reconocido legalmente, tendrá el mismo valor que la escritura pública entre los que la hubiesen suscrito y sus causahabientes», a lo que ha de añadirse que el art. 1.227 de este último texto precisa respecto del importante dato de la fecha, que la del documento privado «no se contará respecto de terceros sino desde el día en que hubiese sido incorporado o inscrito en un registro público, desde la muerte de cualquiera de los que lo firmaron, o desde el día en que se entregase a un funcionario público por razón de su oficio»

Por otro lado, se ha confirmado el abandono de otras categorías, como las de documentos auténticos y no auténticos que efectuaba la LEC anterior hasta su reforma por Ley 34/1984, de 6 de agosto, habida cuenta de las controversias doctrinales que suscitaba.

Lo que, sin embargo, más importa subrayar es la fuerza probatoria que se otorga «ex lege» a documentos públicos y privados y las reglas generales que sobre el particular se contienen en los arts $319 \mathrm{y}$ 326, respectivamente, de la LEC.

El primero de tales preceptos -que, por lo dicho, debe tenerse en cuenta en concordancia con el art 1.218 del C.C., que extiende la fuerza probatoria de los documentos públicos «contra los contratantes y sus causahabientes en cuanto a las declaraciones que en

${ }^{4}$ Su Exposición de Motivos justifica tal proceder en su punto o apartado XI diciendo que se derogan únicamente «los preceptos del Código Civil carentes de otra relevancia que la procesal», es decir, que se mantienen los que tienen una trascendencia material. 
ellos hubiesen hecho los primeros", en lo que constituye una matización y restricción subjetiva de la regla general no prevista en la LEC - parte de la afirmación general de su eficacia probatoria plena «en relación con el hecho, acto o estado de cosas que documenten, así como de la fecha en que se produce dicha documentación y de la identidad de los fedatarios y demás personas que, en su caso, intervengan en ella» (apartado 1), añadiendo que si se trata de documentos administrativos no comprendidos en los n. ${ }^{\circ} 5$ y 6 del art 317 de la LEC a los que las leyes otorguen el carácter de públicos "será la que establezcan las leyes que les reconozca tal carácter», advirtiendo previamente la precitada Exposición de Motivos de la norma de tal diferenciación en su ya mencionado apartado XI al decir que "determinados preceptos de diversas leyes atribuyen carácter de documentos públicos a algunos respecto de los que, unas veces de modo expreso y otras implícitamente, cabe la denominada "prueba en contrario», por lo que la LEC, aun respetando esas disposiciones de otros cuerpos legales, «está obligada a regular diferenciadamente esos documentos públicos y aquellos otros, de los que hasta aquí se ha venido tratando, que por sí mismos hacen prueba plena».

En el supuesto de que tales documentos públicos fuesen impugnados, deberán ser cotejados o comprobados en los términos y con las consecuencias del art 320 de la LEC y con las excepciones contempladas en el 322, dándose reglas especiales para los documentos públicos extranjeros en el art 323.

En cuanto a los privados, el art 326 de la LEC, admite también su eficacia probatoria plena «en los términos del art 319», siempre que «su autenticidad no sea impugnada por la parte a quien perjudiquen», si bien, en este caso, se podrá pedir el cotejo correspondiente o proponerse "cualquier otro medio de prueba que resulte útil y pertinente al efecto», de manera que se establece un procedimiento a instancia de parte y más amplio que el cotejo propiamente dicho, deduciéndose de todo ello que no bastará con la mera impugnación y menos aún con el «desconocimiento» oficial de la otra parte del documento presentado por la contraria, en cuyo caso parece que el Juzgador será libre de evaluar dicha prueba ${ }^{42}$.

42 En la práctica, ésta suele ser la solución habitual, al limitarse la parte contraria a la proponente de la prueba a no reconocer o "desconocer" (pero no impugnar expresamente) el/los documento/s de que se trate y no solicitar acto seguido el cotejo o cualquier otro medio de prueba en los términos referidos y aunque ello es, en la dicción normativa, una mera facultad («podrá») es claro que no está cumpliendo con la segunda parte del contenido de la impugnación propiamente dicha, que exige una referencia de contraste, por lo que cabe entender que esa mera negativa de reconoci- 
En suplicación, el Tribunal deberá tener presente tales reglas para determinar si se ha dado en la sentencia de instancia al documento el valor que realmente posee o si por el contrario, es posible atender a la motivación fáctica que sobre el mismo efectúe la parte recurrente para fundamentar y resolver de modo distinto el litigio.

De antemano, la jurisprudencia ha descartado la naturaleza documental de algunos medios, a los que ha negado, consecuentemente, eficacia revisora, por constituir, en realidad, pruebas de otra cla$\mathrm{se}^{43} \mathrm{o}$ carecer incluso de ese valor ${ }^{44}$, habiendo precisado, por otra parte ${ }^{45}-\mathrm{y}$ probablemente teniendo en cuenta, siquiera sea tácitamente, la diferenciación legal ya apuntada - que un documento público, por sí solo, no tiene prevalencia sobre otras pruebas y que vincula al Tribunal únicamente respecto al hecho que motiva su otorgamiento y de su fecha, pero que no basta para enervar una valoración probatoria conjunta.

Las sentencias de los TTSSJJ, por su parte, han ido desgranando, al decidir la suplicación, el examen de cada uno de los que se sometían a su examen, dando eficacia revisora, entre otros que pueden considerarse de naturaleza pública al amparo del n. ${ }^{\circ} 5$ del referido art 317 de la LEC, a las certificaciones de la TGSS ${ }^{46} \mathrm{o}$ a un certificado del INSALUD ${ }^{47}$, o a un expediente de regulación de empleo ${ }^{48}$, y entre los de naturaleza privada, por ejemplo, al libro de matrícula empresarial ${ }^{49}$, mientras que, por el contrario, ha negado dicha eficacia a las

miento o "desconocimiento" no es una auténtica impugnación sino un sucedáneo de la misma que únicamente supone una llamada de atención al Juzgador y le deja en libertad para que, en uso de su libre decisión en la ponderación global de la prueba, pueda decidir sobre si tal documental refleja o no auténticamente su contenido.

43 SS.TS, Sala 4 . $^{\text {, }}$, de 23 de mayo de 1990 y 28 de febrero de 1991, entre otras, que niegan que sean documentos las manifestaciones ante notario, calificándolas de declaraciones testificales, siendo de reseñar al efecto que se trata de una práctica relativamente habitual y que, en realidad y en aquellos casos en que no son adveradas en juicio, constituyen una testifical impropia que debiera tener, salvo en ocasiones muy concretas y excepcionales, un nulo o mínimo valor probatorio en cuanto que no permiten a la parte contraria hacer uso de su legítimo derecho a repreguntar privando asimismo al Juzgador de instancia - al menos en dicho acto - de solicitar las aclaraciones que estime oportunas.

${ }^{44}$ S.TS, Sala $4 .^{2}$, de 19 de diciembre de 1989, relativa a unas fotocopias no adveradas por quien presuntamente emitiese el texto ni reconocidas de contrario y SS de 16 y 22 de mayo de 1990, entre otras referentes a las actas de juicio.

45 SS. TS, Sala 4. ${ }^{2}$, de 6 de julio de 1995 y 8 de marzo de 1997, citadas por la s. del TSJ de Canarias (Santa Cruz de Tenerife), de 11-11-04.

46 s. Sala de lo Social del TSJ Andalucía (Málaga), de 20-5-96.

47 s. Sala de lo Social del TSJ de La Rioja de 5-12-96.

48 s. Sala de lo Social del TSJ de Andalucía (Málaga) de 29-12-96.

49 s. Sala de lo Social del TSJ de Cantabria de 29-3-96. 
actas del comité de empresa ${ }^{50}$, a los recibos y nóminas ${ }^{51}$ o a los recortes de prensa ${ }^{52}$, siendo de significar, no obstante, que la solución viene dada en cada caso, por lo general, en función de las circunstancias concurrentes en el mismo, con puntuales excepciones, como las meritadas hojas de salario, respecto de las cuales es ya clásica y añeja la tesis de la carencia, en todo caso, de fuerza evidenciadora del error del Juzgador de instancia ${ }^{53}$, o las reseñas periodísticas ${ }^{54}$ igual- $^{2}$ mente precitadas, de las que se ha dicho que tampoco poseen virtualidad al respecto en términos globales, de manera que aunque puedan demostrar el hecho de la publicación no acreditan el que sea objeto de la noticia.

\section{C) LA PRUEBA PERICIAL ${ }^{55}$}

Tal y como la doctrina más autorizada ${ }^{56}$ la define y así lo consagra la vigente $\mathrm{LEC}^{57}$, la pericial es un medio de prueba en el que se emplea a una persona, ajena a los litigantes y que posee especiales conocimientos en la materia, como instrumento productor de la convicción del Juez, emitiendo al efecto declaraciones sobre datos que habían adquirido ya índole procesal en el momento de su captación ${ }^{58}$.

La Ley exige (art 340.1) la titulación oficial correspondiente para el ejercicio de esta actividad, aunque admite que si se tratare de materias que no estén comprendidas en títulos profesionales oficiales,

${ }^{50}$ s. Sala de lo Social del TSJ de Aragón, de 25-9-96.

51 ss. Sala de lo Social del TSJ de Madrid, de 6-11 y 12-12-96.

52 s. Sala de lo Social del TSJ de Murcia, de 10-6-96 (ésta y las demás sentencias que se recogen en las notas precedentes, desde la 42, se relacionan, entre otras, en la nota n. ${ }^{\circ} 10$ de la Parte III, pág 222, del texto de los profesores Montoya Melgar, A., Galiana Moreno, J.M., Sempere Navarro, A.V. y Ríos Salmerón, B., "Curso de Procedimiento Laboral", 5. a edición, Edit. Tecnos, 1998.

53 SS. del TS de 29 de mayo de 1972, 22 y 23 de febrero de 1973 y 7 de marzo de 1974, entre muchas otras, y del TCT de 11 de noviembre de 1974, 5 de febrero y 11 de octubre de 1975, 1 de octubre de 1976, etc, etc.

54 SS. TCT 21 de mayo de 1974 y 13 de enero de 1976, entre otras.

55 Al respecto puede consultarse Duréndez Saiz, I. «La prueba pericial», en «Incidencia de la Ley de Enjuiciamiento Civil en el Procedimiento Laboral», VVAA (Ríos Salmerón, B. y Sempere Navarro, A.V., coordinadores), Edit. Aranzadi, 2001

${ }^{56}$ Guasp, J. obra citada, págs 394 y ss.

57 V. precitado apartado XI de su repetida Exposición de Motivos.

$58 \mathrm{Ha}$ habido, no obstante, autores, igualmente relevantes, que sostenían otra cosa, considerando al perito como un auxiliar del Juez al que ayudaba a valorar los hechos pero sin aportar prueba alguna, como entendía Prieto Castro, L. «Derecho Procesal Civil», Madrid, 1968, tomo I, pág. 509. 
puede haber igualmente peritos, que serán nombrados entre personas entendidas en aquellas materias y cuyo marco de actuación vendrá dado fundamentalmente por aquellos casos en que lo que se precise sea una especial sabiduría fruto de la experiencia o de la práctica de un oficio.

A todo ello se añade, en fin, también como pericial, el contenido de los dictámenes o informes que pueden encargarse a «Academias e instituciones culturales y científicas que se ocupen del estudio de las materias correspondientes al estudio de la pericia» (art 340.2 LEC), precisando el último de los apartados del precepto (340.3) que en esos casos la institución a la que se encargue el dictamen expresará qué persona/s "se encargará/n directamente de prepararlo", a la que se exigirá el juramento o promesa previsto en el apartado segundo del art 335», con lo que cierta manera, se diluye la especificidad de esa pericial, convirtiéndose, de hecho, en una prueba pericial común, aunque puede entenderse que la labor que la norma reserva a la institución no tanto se circunscribe a la de designar entre sus miembros al perito/s sin elaborar el dictamen como tal colegio o corporación, aunque lo haga/n uno o varios de sus miembros, cuanto a respaldar con esa designación la actividad antedicha del miembro/s elegido para dicho cometido el/los cual/es, en realidad "preparan" el dictamen investidos de la especial autoridad que la entidad en cuestión le/s presta con su elección y con el hecho de pertenecer a la misma, lo que supone, de antemano, la asunción por dicha entidad del contenido del mismo y su refrendo.

Como es bien sabido y tanto la doctrina como una clásica jurisprudencia tiene declarado ${ }^{59}$, esta prueba se diferencia fundamentalmente de la testifical en que el conocimiento que perito aporta no deriva de su presencia en el hecho acontecido sino de su especial saber o experiencia.

Sobre esta base, la LPL únicamente determina en su art 95 que el Juez o Tribunal podrá, si lo estima procedente, oír en el momento del acto del juicio o, terminado éste, para mejor proveer, el dictamen de una o varias personas expertas en la cuestión objeto del pleito, cabiendo que igualmente dé audiencia o recabe el informe de la comisión paritaria de un convenio colectivo cuando se discuta en un proceso sobre su interpretación, o, en fin, que asimismo solicite el dictamen de los organismos públicos competentes cuando se haya suscitado una cuestión de discriminación por razón de sexo. En estos

59 V., p.-e., S.TS, Sala de lo Social, de 27 de junio de 1977. 
tres supuestos se ven reflejados, evidentemente, los ya examinados que, con carácter general, enuncia la LEC en su precitado art 340.1, sin que el último (dictamen en materia de posible discriminación por razón de sexo) coincida - al menos plenamente-con el de los apartados 2 y 3 de esa misma norma, porque se trata no del requerimiento a una institución cultural o científica sino a un organismo público, al que se solicita que en tal condición informe al respecto evaluando las circunstancias y datos correspondientes al caso pero sin pronunciarse, evidentemente, sobre las consecuencias que de ello se podrán inferir, lo que únicamente corresponde al Juzgador, de modo que su tarea se limitará, probablemente, al examen contrastado y estadístico del hecho que se somete a su consideración y de las especiales características de éste para justificar, o no, un trato diferente en razón del sexo de la persona afectada ${ }^{60}$.

Antes, el art 77.1 de la misma norma admite como acto preparatorio del proceso, que quien pretenda demandar, solicite del órgano jurisdiccional la comunicación de documentos contables, acudiendo al mismo asesorado de un experto en la materia, lo cual constituye una manifestación de pericia instrumental, y el art 93.2, establece que el órgano judicial, de oficio o a petición de parte, "podrá» requerir la intervención de un médico forense en los casos en que «sea necesario"su informe, lo que no deja de constituir una contradicción.

La ya tratada acta de juicio tiene que recoger, entre otros extremos, según el precitado art 89.1.c), $4 .^{\circ}$ y $5 .^{\circ}$ el resumen suficiente de los informes periciales y lo que judicialmente se haya decidido acerca de las recusaciones propuestas de los peritos, así como de las declaraciones de los asesores en el caso de que su dictamen no se haya elaborado por escrito e incorporado a los autos, de ahí una de las razones de la sobresaliente trascendencia de este documento en vía de recurso, pues a diferencia de lo que acontece en la propia instancia donde el Juzgador tiene una percepción muy clara de la prueba practicada, al haberse desarrollado la práctica de toda ella a su presencia, habiendo incluso podido intervenir en la misma haciendo a las partes, peritos y testigos las preguntas que estime necesarias para esclarecer los hechos, según el art 87.3 de la propia LPL, orde-

${ }^{60}$ La mayor parte de las veces se referirá a la valoración de puestos de trabajo y a la consulta a organismos especializados, que a la vista de los datos suministrados o incluso de lo que deparen entrevistas con los afectados y comprobación de lo oportuno, emiten su parecer sin necesidad de ninguna otra cosa, remitiendo al órgano jurisdiccional el escrito correspondiente. 
nando, por otra parte, si lo estimase necesario y como también se expuso con anterioridad, la prueba pertinente para mejor proveer (art 88.1 LPL), la Sala, carente de la inmediación que aquél disfruta, ha de estar a cuanto se haya recogido en el acta si precisase alguna aclaración a los respectivos informes o dictámenes porque no se hubiese explicado lo suficiente en el texto de la sentencia recurrida.

Respecto, en fin, de la práctica de esta prueba, además de cuanto pueda deducirse de lo ya expuesto, únicamente se especifica en la Ley Procesal Laboral (art 94.1) que no serán de aplicación las reglas generales sobre insaculación de peritos, lo que constituye una tácita pero no por ello menos evidente referencia a la LEC de 1881 (art 616) puesto que la vigente LEC es posterior a la ley laboral y establece al respecto normas nuevas en sus arts 341 y concordantes.

Es claro que aun cuando no lo prevea el art 76.2 de la LPL, dicha prueba puede ser propuesta y practicada, al amparo del art 293 de la LEC antes de la presentación de la demanda cuando exista el temor fundado de que por causa de las personas o por el estado de las cosas dicho acto no pueda realizarse en el momento procesal previsto para ello.

De otro lado, y conforme al art 78 de la LPL, también puede interesarse y realizarse dicha prueba después de presentada la demanda y antes del juicio oral si en éste no va a ser posible llevarla a cabo o existan graves dificultades para ello, no cabiendo recurso alguno contra la resolución denegatoria y sin perjuicio del que por este motivo pueda interponerse en su día contra la sentencia.

Es necesaria la adveración en juicio del dictamen o informe por quien lo hubiera emitido, respondiendo a cuantas cuestiones, que se declaren pertinentes (art 87.2 LPL), le plantee la parte que lo hubiere propuesto y después la contraria ${ }^{61}$, e incluso, como se ha dicho ya, el propio Juzgador.

De no producirse el referido reconocimiento a la presencia judicial -lo que es consecuencia de la aplicación al proceso laboral, con sus caracteres propios, del art 346 de la LEC - y no dándose a la parte oponente la posibilidad de instar tales aclaraciones, la pericial devendrá en una documental privada, carente, por otra parte, de garantías de autenticidad, a menos que, siquiera sea en esta última

${ }^{61}$ Porque ,como dice la s. de la Sala de lo Social del TSJ de Castilla-León (Burgos) de 16-11-96, en la práctica de este medio de prueba rige el principio de contradicción en garantía de la parte contraria, que podrá formular preguntas y efectuar objeciones al perito informante. 
condición, sea reconocida de adverso. Algo distinto son los dictámenes médicos de las entidades gestoras de la seguridad social y de las prestaciones asistenciales, que al formar parte del expediente administrativo, no precisan, en principio al menos, tal adveración.

No cabe olvidar, por otra parte, que el art 352 de la LEC se refiere a otros dictámenes periciales instrumentales de pruebas distintas (medios de prueba admitidos por el tribunal al amparo de lo previsto en los apartados 2 y 3 del art 299) cuando sea necesario o conveniente para conocer el contenido o sentido de una de ellas o para proceder a su más acertada valoración.

En cuanto a esta última, en fin, el art 348 de la LEC dispone que «el tribunal valorará los dictámenes periciales según las reglas de la sana crítica». Se trata de una noción abstracta, que otorga, por tanto, un amplio margen de discrecionalidad al órgano judicial, aun cuando ello supone, como contrapartida, la responsabilidad de su actuación con una dosis suficiente de lógica que ha de plasmarse en la fundamentación jurídica de la sentencia.

De ello se infiere que aunque en teoría esta prueba sea perfectamente idónea para propiciar la revisión fáctica en la alzada, en la práctica no tendrá lugar dicha revisión si el Juzgador no ha incurrido en un evidente error en la ponderación probatoria o en una contradicción flagrante entre lo que dice probado y la conclusión que obtenga al respecto.

Merece la pena detenerse, por último, en el examen de la prueba pericial en uno de sus ámbitos más caracterizados, como es el de las prestaciones de seguridad social por incapacidad, - extensible, en líneas generales, a las minusvalías de la asistencia no contributiva-y todas aquéllas que, en definitiva, exijan informes o dictámenes médicos, donde, como se ha dicho en suplicación ${ }^{62}$, la jurisprudencia ha venido a determinar cuáles son los contornos de esa protección en nuestro sistema, y cómo debe de realizarse la valoración de las dolencias del trabajador que, siendo objetivables, sean tenidas previsiblemente como definitivas, tal y como finalmente queden judicialmente acreditadas, lo que se puede resumir en los siguientes términos:

a) Que debe de acomodarse la decisión que en cada supuesto se deba de adoptar, a un necesario proceso de individualización, en

${ }^{62}$ V. s. TSJ Navarra de 22-11-02, que expresa y relaciona cuanto a continuación se reproduce y la jurisprudencia de las notas que siguen, hasta la 77 inclusive. 
atención a cuáles sean las concretas "particularidades del caso a enjuiciar ${ }^{63}$, que lo diferencian de las situaciones de otros distintos afectados, tanto por la incidencia de otras lesiones, como por la concreta actividad desempeñada por el mismo, que es la determinante a efectos de esa valoración, teniendo en cuenta la desarrollada, en su caso, en el momento del percance o del inicio de la situación de baja o de solicitud de la valoración invalidante ${ }^{64}$.

b) Derivado de lo anterior, debe realizarse dicho proceso valorativo y de subsunción normativa, en atención a cuáles sean los "hechos singulares» del caso ${ }^{65}$, pues lesiones que aparentemente son idénticas, o bien pueden diferenciarse en su concreta graduación, o bien afectar de modo distinto a los diversos trabajadores, o tener un distinto alcance en cuanto a su particular repercusión funcional ${ }^{66}$.

c) Ello conduce, en la práctica, a la casi imposibilidad de poder llegar a una generalización de soluciones homogéneas en esta materia $^{67}$, que son muy casuísticas cuando se refieren a la concreta determinación del grado invalidante, dificultando así la necesaria evidencia de la existencia de contradicción entre diversas soluciones judiciales de distintas Salas de lo Social de los diferentes Tribunales Superiores de Justicia, que permita, conforme al artículo 217 de la Ley de Procedimiento Laboral, el acceso de las soluciones judicialmente adoptadas a la unificación de doctrina ${ }^{68}$.

d) Que, dado el carácter marcadamente profesional de nuestro Sistema de protección social en relación con la invalidez, lo que interesa valorar es, cuál sea la capacidad laboral residual que, las secuelas que han sido tenidas como definitivas, permiten al afectado. $Y$ ello, bien sea para la que haya venido siendo su profesión habitual hasta el momento de acaecer la incidencia presuntamente invalidante $^{69}$, o bien, en general, para cualquier otra actividad u oficio. De donde derivará una u otra calificación de las mismas, de acuerdo con los distintos tipos invalidantes que vienen legalmente previstos, actualmente en el artículo 137 de la Ley General de la Seguridad Social (parcial, total, o absoluta).

${ }^{63}$ SS. TS, Sala 4. ${ }^{\text {a }}$, de 2 de abril de 1992 y 29 de enero de 1993, entre otras.

${ }^{64}$ S. TS, Sala $4 .^{\text {a }}$, de 23 de noviembre de 2000.

65 SS. TS, Sala 4. a, de 17 de marzo de 1989, 27 de noviembre de 1991 y 9 de abril de 1992, entre otras.

66 S. TS, Sala 4. ${ }^{\text {a }}$, de 25 de enero de 2000.

67 S.TS., Sala 4. ${ }^{\text {a }}$, de 9 de marzo de 1995.

${ }^{68} \mathrm{~S}$. TS, Sala 4. ${ }^{\mathrm{a}}$, de 27 de enero de 1997, entre otras.

${ }^{69}$ S. TS, Sala $4 .^{\text {a }}$, de 23 de noviembre de 2000 , ya citada. 
e) Que esa valoración de teórica capacidad laboral tiene que verificarse teniendo en cuenta que la prestación de un trabajo o actividad debe ser realizada en condiciones normales de habitualidad, de modo que con un esfuerzo normal se pueda obtener el rendimiento que sea razonablemente exigible ${ }^{70}$, sin que, por lo tanto, sea precisa la realización, por parte del sujeto afectado, de un sobreesfuerzo que deba ser tenido como especial ${ }^{71}$, y además, prestando ese trabajo concreto, o desarrollada la actividad, tanto con la necesaria profesionalidad ${ }^{72}$, como conforme a las exigencias normales de continuidad, dedicación y eficacia, que son legalmente exigibles ${ }^{73}$, y consecuentemente, con desempeño de un modo continuo y de acuerdo con la jornada laboral que sea la ordinaria en el sector de actividad o en la empresa concreta $^{74}$.

Consecuentemente con todo ello, más que de incapacidades en general, de lo que tiene que hablarse - continúa esa jurisprudencia-- ${ }^{75}$ es de incapacitados, al tenerse que decidir, en cada caso litigioso, conforme al mencionado artículo 137 de la Ley General de la Seguridad Social, en atención a cuáles sean sus concretas y particulares circunstancias $^{76}$, en cuanto que en materia de invalidez, como ya se ha indicado, difícilmente pueden darse supuestos con una identidad sustancial.

Por consiguiente, que cada situación se decide en función de todas y sus particulares circunstancias ${ }^{77}$, es decir, atendiendo a la "especificidad litigiosa» del caso, lo que le otorga a la prueba pericial una importancia sobresaliente en este tipo de asuntos, dada la naturaleza de los mismos y el objeto de la controversia.

\section{LA DOCUMENTAL APORTADA CON EL RECURSO DE SUPLICACIÓN}

Entre las disposiciones comunes a los recursos de suplicación y casación, el art 231 de la LPL establece un mandato imperativo dirigido

70 S. TS, Sala 4. a , de 22 de septiembre de 1989.

71 S. TS, Sala $4 .{ }^{a}$, de 22 de septiembre de 1989 , entre otras.

72 S. TS, Sala $4 .^{\text {a }}$, de 14 de febrero de 1989.

${ }^{73}$ S. TS., Sala $4 .^{2}$, de 7 de marzo de 1990.

74 SS. TS, Sala 4. ${ }^{\text {, }}$, de 16 de febrero de 1989 y de 23 de febrero de 1990, entre otras.

${ }^{75}$ S. TS., Sala $4 .^{\text {a }}$, de 24 de enero de 1991.

76 S. TS., Sala $4{ }^{a}$, de 20 de abril de 1992 y 11 de abril de 1995 , entre otras.

77 S. TS, Sala 4. ${ }^{\text {, }}$, de 3 de marzo de 1998. 
a las Salas respectivas por el que éstas no podrá admitir a las partes documento alguno que no resulten de los autos, estableciendo, no obstante, como excepción que «si el recurrente presentara algún documento de los comprendidos en el art 506 de la LEC o escrito que contuviese elementos de juicio necesarios para evitar la vulneración de un derecho fundamental, la Sala, oída la parte contraria dentro del plazo de tres días, dispondrá en los dos días siguientes lo que proceda, mediante auto motivado contra el que no cabrá recurso alguno".

La exégesis de dicho precepto requiere efectuar las siguientes consideraciones:

a) Que la regla general es la inadmisibilidad de documentos y alegaciones de hechos que no resulten de los autos en vía de recurso.

b) Que excepcionalmente cabe tal aportación en dos supuestos, el primero, con base en un precepto de una norma ya derogada, que se corresponde con el actual art 270 de la vigente LEC, que contempla, a su vez, tres posibles situaciones que, acomodadas a las características del proceso laboral, son las siguientes: 1) que el/los documento/s sea de fecha posterior a la demanda y a la contestación, es decir, al juicio oral, siempre que no se hubiese/n podido confeccionar ni obtener con posterioridad a dichos momentos procesales; esta última precisión, introducida por la nueva Ley, supone que no cabe, por ejemplo, aportar una certificación con fecha posterior pero que pudo haberse obtenido antes del juicio y que si no se hizo así fue por causa únicamente imputable a la parte; 2) que se trate de documentos, medios o instrumentos anteriores al juicio, cuando la parte que los presente justifique no haber tenido antes conocimiento de su existencia, lo cual supone que se acredite o, cuanto menos y según las circunstancias del caso, se dé una explicación convincente al respecto; $y$, en fin, 3) que dicha parte no haya podido obtener con anterioridad los documentos, medios o instrumentos por causas que no sean imputables a la parte, siempre que haya hecho oportunamente la designación o, en su caso, el anuncio legalmente prescritos, lo cual trasladado al proceso laboral implica tener en cuenta lo preceptuado y ya referenciado acerca de los actos preparatorios y medidas precautorias, así como de la solicitud anticipada de prueba y de requerimiento de aportación al proceso, de modo que este supuesto es, probablemente, el que mayor complicación ofrece en su aplicación.

La otra excepción, encaminada a evitar la vulneración de un derecho fundamental, alude a «elementos de juicio» necesarios a tal fin y contenidos en el escrito que se trata de presentar, debiendo con- 
sistir tales elementos, según la doctrina, ${ }^{78}$ en hechos y no en valoraciones o argumentaciones jurídicas, los cuales han de ser posteriores al momento en que pudieron alegarse por dicha parte o de imposible conocimiento por la misma entonces y han de estar relacionados con la cuestión debatida.

c) Que esa posibilidad queda circunscrita a la parte recurrente, de modo que no es extensible a la contraria, de igual manera que tampoco puede ésta solicitar en su escrito de impugnación modificación o revisión fáctica alguna.

d) Que el momento de intentar su presentación será con el recurso, o incluso después, pero antes, en todo caso, del trámite de deliberación votación y fallo, que será previa y oportunamente notificado a las partes. Esta doble posibilidad, tiene, a su vez, dos consecuencias distintas y recíprocamente excluyentes en función de la diferente situación creada: que si la documentación referida se presenta con el recurso, la Sala podrá decidir acerca de la admisibilidad de aquélla sin necesidad de dar traslado expreso a la parte contraria comparecida, pues ésta habrá conocido ya dicha prueba cuando se le dio traslado del recurso para su posible impugnación y tuvo entonces ocasión de manifestarse al respecto; por el contrario, si la prueba pretendida se aporta mientras el recurso sigue su curso ante la Sala, ésta deberá dar audiencia al respecto a la parte opuesta.

e) Que la solución que el Tribunal adopte será mediante auto, contra el que no cabrá recurso de sùplica, y precisamente por esta inimpugnabilidad de la resolución, es posible que, por economía procesal, se adopte dentro de la sentencia que resuelva el recurso dedicándole un primer fundamento de derecho, que ni siquiera será necesario cuando la Sala entienda que existe falta de jurisdicción, aunque ello, de no haberse planteado en la instancia, exigirá audiencia previa de las partes y del Ministerio Fiscal conforme al art 9.6 de la LOPJ y 38 de la LEC, o, en fin, cuando estime que por razón de la cuantía o de la naturaleza del asunto, no cabe recurso contra la sentencia de instancia, pues todo ello, aunque no hubiese sido alegado de adverso y/o la sentencia de instancia razonase o manifestase que cabe recurso de suplicación contra la misma, es también cuestión de orden público procesal, por afectar a la competencia funcional, que debe resolverse prioritariamente, incluso de oficio.

${ }_{78}$ V. Cavas Martínez, F., trabajo citado, que se remite, en este punto, a Montero Aroca, J., obra igualmente mencionada y a Desdentado Bonete, A. «Recursos de suplicación y casación. Disposiciones comunes" en "Diccionario Procesal Social", VVAA, Edit Civitas, 1996, pág. 720. 